\title{
Unsubstituted $\beta$-Alkyl Aspartates as Highly Biodegradable and Almost Nontoxic Surfactants
}

\author{
Sindija Brica, Maris Klavins, Andris Zicmanis* \\ University of Latvia, Riga, Latvia \\ Email: zicmanis@latnet.Iv
}

Received 11 July 2016; accepted 8 August 2016; published 11 August 2016

Copyright (C) 2016 by authors and Scientific Research Publishing Inc.

This work is licensed under the Creative Commons Attribution International License (CC BY).

http://creativecommons.org/licenses/by/4.0/

(c) (i)

Open Access

\begin{abstract}
Zwitterionic surfactants $-\beta$-alkyl aspartates are prepared by the addition reaction of ammonia to alkyl maleates. Factors are discussed that influence the quality and yields of obtained $\beta$-alkyl aspartates. Structures of obtained surfactants are confirmed by ${ }^{1} \mathrm{H}$ NMR and IR spectra. The applicability of these materials is characterized by evaluation of their surface activity, toxicity and biodegradability.
\end{abstract}

\section{Keywords}

\section{Biodegradability, Surface Tension, Synthesis, Toxicity, Zwitterionic Surfactants}

\section{Introduction}

No washing or cleaning process is imaginable without an exploitation of detergents with surface-active substances (surfactants) as their integral ingredient. Zwitterionic (amphiphilic) surfactants form probably the youngest group in the widespread surfactant family. The need for production and utilization of environmentally friendly surfactants grows together with the substantial increase of volumes of their consumption nowadays. Requirements for modern surfactants are quite severe - they should be highly efficient in washing and/or cleaning processes, non-toxic (or at least only slightly toxic), biodegradable (capable to decompose after entering into the environment in a reasonable time), and sufficiently low-cost materials allowing customers purchasing them in a necessary quantity. Clearly recognizing the need for such advanced materials as a contemporary problem, results of our recent investigations about the elaboration of modern surfactants are presented in the communication. The proposed surfactants correspond to all four claims mentioned above. An idea is proposed (as a hypo-

*Corresponding author.

How to cite this paper: Brica, S., Klavins, M. and Zicmanis, A. (2016) Unsubstituted B-Alkyl Aspartates as Highly Biodegradable and Almost Nontoxic Surfactants. Green and Sustainable Chemistry, 6, 125-135.

http://dx.doi.org/10.4236/gsc.2016.63012 
thesis) that surfactants containing a nonsubstituted amino group in $\alpha$-amino acid-aspartic acid might correspond better to high claims mentioned above than $N$-substituted derivatives of amino acids. Such surfactants would have hydrophilic parts that were very similar to amino acids of the animal world and therefore might become easily degradable by microorganisms. They would maintain a high surface activity due to the hydrophobic alkyl chains in their $\beta$-ester groups at the same time. The proposed surfactants are a little bit similar to famous lysine derivatives acylated at $\omega$-nitrogen atom, these lysine derivatives being considered as highly efficient detergents nowadays [1]-[3]. The amide bond at $\omega$ - $N$ atom makes lysine derivatives less biodegradable than materials proposed in the present communication $-\beta$-alkyl aspartates that contain ester bonds, the last entering hydrolysis reactions very much easier than amides.

Several synthetic methods for the preparation of zwitterionic surfactants have obtained full recognition nowadays. They include chemical or enzymatic transformation of amino acids into their esters, conversion of amino acids into their derivatives with hydrophobic $N$-alkyl or $N$-acyl group at the nitrogen atom, as well as addition of fatty primary amines to the $\mathrm{C}=\mathrm{C}$ double bonds of $\alpha, \beta$-unsaturated acids or their derivatives [4]-[11]. All these methods have allowed manufacturing surfactants with excellent washing and cleaning properties as well as acceptable biological properties. It should be emphasized at the same time, that substituted $\alpha$-amino acids have formed in all these transformations containing long chains of carbon atoms at $\alpha-O$ - or $\alpha-N$-atoms. Surfactants containing nonsubstituted $\alpha$-amino acid moiety in their hydrophilic part are prepared few and far between [10]-[13]. Enzymatic and synthetic methods have provided various yields of such zwitterionic surfactants, the yields of derivatives of amino dicarboxylic acids usually being somehow lower. For example, the best yield of $\beta$-dodecyl aspartate was only $40 \%$ when aspartic acid and 1-dodecanol were transformed into the mono-dodecyl aspartate in the presence of sulfuric acid [14].

A different approach to the synthesis of $\beta$-alkyl aspartates is considered in the present communication-addition of ammonia to hemiesters of maleic acid. It would rehabilitate alkyl aspartates, if successful, and make them available to the large community of users. Surfactants prepared this way would contain a non-substituted $\alpha$-amino acid in its hydrophilic part and a long linear alkyl chain connected to the oxygen atom of $\beta$-ester group in its hydrophobic part. Therefore, it is expected that these surfactants will be less toxic and much better biodegradable substances than derivatives of $N$-substituted $\alpha$-amino acids used nowadays as surfactants and will maintain the well-known excellent washing and cleaning properties characteristic for materials of this group.

Therefore, the objective of the communication is to propose a group of new surfactants that are marginally close to natural substances - hemiesters of aspartic acid and a way of their synthesis. These substances may have advanced properties by comparison with existing surfactants.

\section{Experimental}

\subsection{Synthesis of $\beta$-Dodecyl Aspartate (2b)}

Dodecyl maleate $(\mathbf{1 b}, 5.68 \mathrm{~g}, 20 \mathrm{mmol})$ and a solution of ammonia in tetrahydrofuran (THF, $90 \mathrm{~mL}, 600 \mathrm{mmol}$, conc. $6.67 \mathrm{~mol} / \mathrm{L}$ ), were placed in a closed steel reactor with a magnetic stirrer and stirred at $50^{\circ} \mathrm{C}$ for 24 hours with stirring rate $300 \mathrm{rpm}$. After that the reactor was cooled to room temperature, opened, the solution was poured into a conical flask and placed in the refrigerator for 48 hours. The precipitate formed was separated by filtration (with suction, on a Büchner funnel), and dried in a vacuum desiccator over $\mathrm{P}_{2} \mathrm{O}_{5}$ for 24 hours. After recrystallization from methanol, $\beta$-dodecyl aspartate $(\mathbf{2} \mathbf{b}, 4.02 \mathrm{~g}, 66.7 \%)$ was obtained in a form of white crystals with m.p. $116^{\circ} \mathrm{C}-117^{\circ} \mathrm{C}$. ${ }^{1} \mathrm{H}$ NMR spectrum (400 MHz, $\left.\mathrm{CDCl}_{3}, \mathrm{Me}_{4} \mathrm{Si}, \mathrm{ppm}\right) \delta: 4.04(\mathrm{~m}, 2 \mathrm{H}), 3.91$ (m, $\left.1 \mathrm{H}\right), 3.01$ $(\mathrm{m}, 2 \mathrm{H}), 1.60(\mathrm{~s}, 2 \mathrm{H}), 1.26(\mathrm{~m}, 19 \mathrm{H}), 0.88(\mathrm{t}, 3 \mathrm{H})$. IR spectrum (neat, $\left.\mathrm{v}_{\max }, \mathrm{cm}^{-1}\right): 3199(\mathrm{O}-\mathrm{H}), 2918(\mathrm{C}-\mathrm{H}), 1729$ $(\mathrm{C}=\mathrm{O}), 1621\left(\mathrm{NH}_{2}\right), 1363(\mathrm{C}-\mathrm{N}), 1244(\mathrm{C}-\mathrm{O})$.

The filtrate of the aspartate (2b) synthesis was turned in a dense oil after the evaporation of it in vacuum. The oil was extracted with hexane $(3 \times 25 \mathrm{~mL})$, and the joint hexane extract was evaporated in vacuum. As a result, 1-dodecanol (6b, $1.53 \mathrm{~g}, 25.3 \%)$ was obtained in the form of a solid with m.p. $25^{\circ} \mathrm{C}-26^{\circ} \mathrm{C}$. The solid residue left after the extraction $(0.30 \mathrm{~g}, 5.1 \%)$ had after crystallization from water m.p. $217^{\circ} \mathrm{C}-220^{\circ} \mathrm{C}$ (decomposition) and had turned out to be $D, L$-asparagine (5). Both isolated substances did not give any depression of m.p. with corresponding pure substances and had identical ${ }^{1} \mathrm{H}$ NMR spectra with them.

Other $\beta$-alkyl aspartates (2a, 2c, 2d) were prepared in a similar way, and their characteristics are presented in Table 1. Syntheses of aspartates (2) were always accompanied by some ammonolysis reaction of $\beta$-ester groups 
Table 1. Chemical and spectroscopic characteristics of $\beta$-alkyl aspartates (2).

\begin{tabular}{|c|c|c|c|c|c|c|c|c|c|c|}
\hline \multirow{2}{*}{ Surfactant } & \multicolumn{2}{|c|}{${ }^{1} \mathrm{H}$ NMR spectra } & \multicolumn{3}{|c|}{ IR spectra } & \multirow{2}{*}{ m.p., ${ }^{\circ} \mathrm{C}$} & \multirow{2}{*}{$\begin{array}{l}\text { Molecular } \\
\text { formula }\end{array}$} & \multicolumn{3}{|c|}{ Elemental analysis, $\%$} \\
\hline & $\mathrm{O}-\mathrm{CH}_{2-}$ & $\mathrm{NCH}-\mathrm{CO}_{2}$ & $v_{\mathrm{NH} 3}$ & $v_{\mathrm{C}=\mathrm{O}}$ & $v_{\mathrm{CO} 2}$ & & & $\mathrm{C}$ & $\mathrm{H}$ & $\mathrm{N}$ \\
\hline \multirow{2}{*}{$2 a$} & \multirow{2}{*}{4.03} & \multirow{2}{*}{3.90} & \multirow{2}{*}{1615} & \multirow{2}{*}{1732} & \multirow{2}{*}{2874} & \multirow{2}{*}{$125-127$} & \multirow{2}{*}{$\mathrm{C}_{20} \mathrm{H}_{39} \mathrm{NO}_{4}$} & 66.98 & 10.76 & 3.47 \\
\hline & & & & & & & & $\overline{67.19}$ & $\overline{10.99}$ & $\overline{3.92}$ \\
\hline \multirow{2}{*}{$2 \mathrm{~b}$} & \multirow{2}{*}{4.04} & \multirow{2}{*}{3.87} & \multirow{2}{*}{1617} & \multirow{2}{*}{1729} & \multirow{2}{*}{2850} & \multirow{2}{*}{$142-143$} & \multirow{2}{*}{$\mathrm{C}_{16} \mathrm{H}_{31} \mathrm{NO}_{4}$} & 63.17 & 10.09 & 4.11 \\
\hline & & & & & & & & $\overline{63.75}$ & $\overline{10.37}$ & $\overline{4.65}$ \\
\hline \multirow{2}{*}{$2 c$} & \multirow{2}{*}{4.03} & \multirow{2}{*}{3.87} & \multirow{2}{*}{1617} & \multirow{2}{*}{1729} & \multirow{2}{*}{2864} & \multirow{2}{*}{$162-167$} & \multirow{2}{*}{$\mathrm{C}_{14} \mathrm{H}_{27} \mathrm{NO}_{4}$} & 61.11 & 9.27 & 4.87 \\
\hline & & & & & & & & $\overline{61.51}$ & $\overline{9.96}$ & $\overline{5.12}$ \\
\hline \multirow{2}{*}{ 2d } & \multirow{2}{*}{4.03} & \multirow{2}{*}{3.90} & \multirow{2}{*}{1615} & \multirow{2}{*}{1727} & \multirow{2}{*}{2843} & \multirow{2}{*}{$175-178$} & \multirow{2}{*}{$\mathrm{C}_{12} \mathrm{H}_{23} \mathrm{NO}_{4}$} & 58.12 & 9.17 & 5.43 \\
\hline & & & & & & & & $\overline{58.75}$ & $\overline{9.49}$ & $\overline{5.71}$ \\
\hline 20 & 402 & 387 & 1617 & 1720 & 2855 & $182-185$ & $\mathrm{C}_{\mathrm{H}} \mathrm{H} \mathrm{NO}$ & 54.72 & 8.32 & 6.05 \\
\hline $2 \mathrm{e}$ & 4.03 & 3.01 & 1011 & 1729 & 2035 & $102-105$ & $\mathrm{C}_{10} \mathrm{CH}_{19 \mathrm{~N} \mathrm{~V}} 4$ & $\overline{55.28}$ & $\overline{8.81}$ & $\overline{6.45}$ \\
\hline
\end{tabular}

giving the corresponding primary fatty alcohols (6) and asparagine (5) which can be easily separated as disclosed above.

\subsection{Determination of Critical Micelle Concentration of the Synthesized $\beta$-Alkyl Aspartates (2)}

Surface tension measurements were carried out on a Sigma 70 tensiometer (KSV) using the du Noüy ring method. The temperature was kept at $25^{\circ} \mathrm{C}\left( \pm 0.01^{\circ} \mathrm{C}\right)$ by a cryostat Neslab RTE-200. The glassware was cleaned with chromosulfuric acid, and the ring was burned prior to use. Critical micelle concentrations (CMC) were calculated from plots of these measurements.

\subsection{Determination of the Toxicity of $\beta$-Dodecyl Aspartate ( $2 \mathrm{~b}$ )}

Daphtoxkit $\mathrm{F}^{\mathrm{TM}}$ magna assay (MicroBio Tests Inc., Gent, Belgium) with crustaceans Daphnia magna was performed according to the standard operational procedure and based on $24 \mathrm{~h}$ and $48 \mathrm{~h}$ incubation of neonates, previously hatched from ephippia during $72 \mathrm{~h}$ and pre-fedded with a suspension of Spirulina microalgae $2 \mathrm{~h}$ prior to testing [14]. Dilutions of the surfactant (2b) were made in standard freshwater and ranged from $0.5 \mathrm{mg} \cdot \mathrm{L}^{-1}$ to $100 \mathrm{mg} \cdot \mathrm{L}^{-1}$.

A Rapidtoxkit assay with larval crustaceans Thamnocephalus platyurus was performed according to the standard operational procedure and based on inhibition of colored particles uptake by stressed (intoxicated) organisms [15]. Dilutions of surfactant (2b) were made in standard freshwater in the range of $0.78-50.00 \mathrm{mg} \cdot \mathrm{L}^{-1}$. Incubation of $T$. platyurus was performed with test chemicals $(5 \mathrm{~mL})$ for $60 \mathrm{~min}$ at $25^{\circ} \mathrm{C}$. After that $0.2 \mathrm{~mL}$ colored beads were added to test tubes. After $30 \mathrm{~min}, 3$ drops of Fixative were added to test tubes. After 5 min, all larvae were dead and settled at the bottom of the tube. Organisms were collected and observed under the dissectionmicroscope (CETI, Belgium). The total number of larvae and the number of larvae with clearly colored digestive tracts were counted. Mean percentage inhibition of particle uptake $(\mathrm{P})$ was calculated by the following equation:

$$
\mathrm{P}=\frac{\mathrm{A}-\mathrm{B}}{\mathrm{A}} \times 100,
$$

where $\mathrm{A}$-mean percentage particle uptake in the control; $\mathrm{B}$ - mean percentage particle uptake in the sample.

\subsection{Determination of the Biodegradability of $\beta$-Dodecyl Aspartate ( $2 \mathrm{~b}$ )}

The values of biodegradability (biological oxygen demand during 3 days, $\mathrm{BOD}_{3}$ ) were determined by using the manometricrespirometric OxiTop ${ }^{\circledR}$ OC100 device (WTW GmbH, Weilheim, Germany). Each set was performed in duplicate. $90 \mathrm{~mL}$ Bushnell Haas broth $\left(\mathrm{g} \mathrm{L}^{-1}: \mathrm{MgSO}_{4}-0.2 ; \mathrm{CaCl}_{2}-0.02 ; \mathrm{KH}_{2} \mathrm{PO}_{4}-1.0 ; \mathrm{K}_{2} \mathrm{HPO}_{4}-\right.$ $1.0 ; \mathrm{NH}_{4} \mathrm{NO}_{3}-1.0 ; \mathrm{FeCl}_{3}-0.05$ ), $\mathrm{pH} 7.0$ was used. $10 \mathrm{~mL}$ of surfactant $(\mathbf{2 b})$ (stock concentration $100 \mathrm{mg} \cdot \mathrm{L}^{-1}$ ) were added to the broth. Bacterial consortium with hydrocarbon degrading activity consisted of five Stenotro- 
phomonas maltophilia and three Pseudomonas spp. strains $\left(3 \mathrm{~mL}\right.$ with concentration $\left.1.2 \times 10^{8} \mathrm{CFU} \mathrm{mL}^{-1}\right)$ was inoculated [16]. Data on manometric measurements were transferred to the computer using AchatOC (WTW $\mathrm{GmbH}$, Weilheim, Germany) soft ware after 3-day incubation at $20^{\circ} \mathrm{C}$ with magnetic stirring.

\section{Results and Discussion}

\subsection{Synthesis of $\beta$-Alkyl Aspartates-General Considerations}

Advanced surfactants $-\beta$-alkyl aspartates (2) were prepared in our laboratory by addition of ammonia to several alkyl maleates (1), the reaction proceeding according to the equation shown in Figure 1. Hence, a residue of $\alpha$-amino acid without any substituent at nitrogen and oxygen atoms was incorporated in the structure of prepared surfactants (2). Therefore, obtained surfactants (2) might be very much better known substances for microorganisms, which decompose them after their exploitation and entering into the environment, by comparison with derivatives of $N$-alkyl or $N$-acyl $\alpha$-amino acids in similar surfactants. Such a structural analogy with $\alpha$-amino acids might allow further improvement the biodegradability of proposed surfactants (2).

The rate of the addition of ammonia to maleic hemiesters (1) depends on several factors- the solvent used in the reaction, temperature of the process, reaction time, and the molar ratio of reagents. Therefore, all these factors were systematically investigated. Unfortunately, the seemingly simple addition reaction was accompanied by side reactions - the rearrangement of maleic hemiesters (1) into fumaric hemiesters (3), the last entering into the ammonia addition reactions more reluctantly than maleic hemiesters (1), as well as ammonolysis of the maleic hemiesters (1) into maleic hemiamides (4) or transformation of the reaction products- $\beta$-alkyl aspartates (2) into asparagine (5); fatty alcohols (6) eliminated in both last reactions. The mentioned undesirable side reactions decreased the yields of $\beta$-alkyl aspartates (2) and incommoded the purification of the surfactants.

Results of the above-mentioned side reactions could be easily observed in ${ }^{1} \mathrm{H}$ NMR spectra of technical products of these addition reactions.

Firstly, resonanse signals of protons at $\mathrm{HC}=\mathrm{CH}$ bond were placed in different places in spectra-they could be found at $6.35 \mathrm{ppm}$ in spectra of maleates (1) versus 6.51 and $6.01 \mathrm{ppm}$ in spectra of fumarates (3), according to our measurements. The isomerisation of maleates (1) into fumarates (3) was catalysed, most likely, by ammonia. Consequently, addition of ammonia to the alkyl maleate can be followed by its elimination from the $\beta$ alkyl aspartates (2).

Secondly, resonance signals of protons placed at $\alpha$-carbon atoms in the eliminated fatty alcohols (6) $\left(\mathrm{HO}-\mathrm{CH}_{2}-\mathrm{R}^{1}\right)$ with $\delta 3.63-3.61 \mathrm{ppm}$ differed noticeably from similar signals of protons in ester groups $\left(-\mathrm{CO}-\mathrm{O}-\mathrm{CH}_{2}-\mathrm{R}^{1}\right)$ at $\delta$ $4.05-4.03 \mathrm{ppm}$. Therefore, chemical shifts of these signals together with measurements of their integral intensities presented an excellent insight into the quantitative part of accompanying side reactions, at least approximately, considering low accuracy of the integration of resonance signals.

Both alkyl maleates (1) and $\beta$-alkyl aspartates (2) may enter the mentioned ammonolysis reaction, transforming into maleamide (4) or asparagine (5), correspondingly, the fatty alcohols (6) eliminating in both these reactions. In order to confirm the statement, the residue obtained after the separation of $\beta$-dodecyl aspartate (2b) from the reaction mixture was investigated more carefully. After extraction of 1-dodecanol $(\mathbf{6 b})$ from the reaction

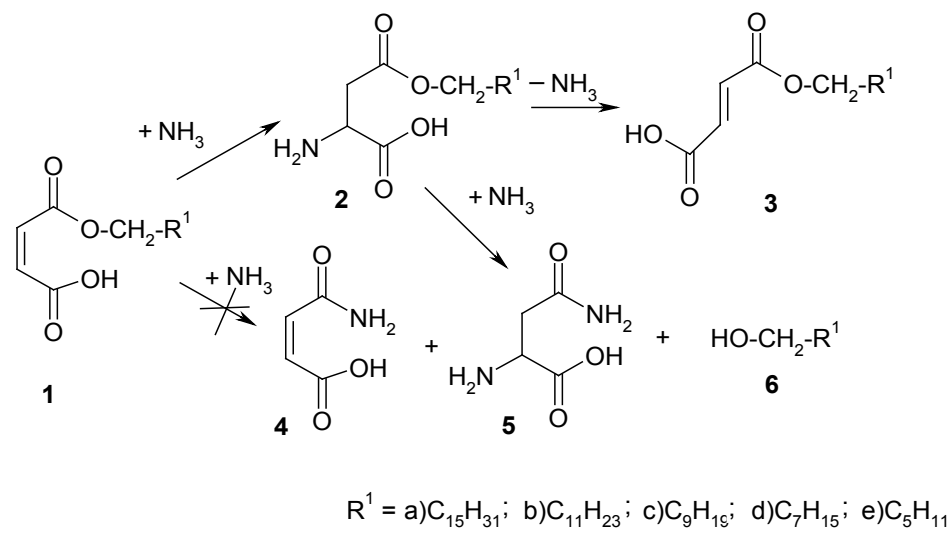

Figure 1. Products of the addition reaction of ammonia to alkyl maleates. 
residue with hexane, a white solid was remained that has turned out to be an individual substance $-D, L$-asparagine (5). This fact excludes the formation of maleamide (4) as a side reaction during the transformation of maleates (1) into surfactants (2). The decrease of the yields of surfactants (2) also implicitly adverted to the competitive elimination reaction during prolonged addition reaction time (48 hours and more). Moreover, the behavior of pure $\beta$-dodecyl aspartate (2b) was tested singly in circumstances approximated to conditions of its synthesis - heating of the surfactant (2b) with ammonia in THF at $50^{\circ} \mathrm{C}$. Tests after 6; 24 and 48 hours have confirmed significant disappearance of $\beta$-dodecyl aspartate (2b) in the reaction mixture $(17.6,31.8$ and $63.0 \%$ correspondingly), and the appearance of $D, L$-asparagine (5), aspartic acid and dodecanol (6b) in the mixture of products $\left(81.7 \%, 67.3 \%\right.$ and $36.0 \%$ correspondingly, according to our HPLC data). The same tests at $100^{\circ} \mathrm{C}$ showed the presence of a considerable amount of fumaric ester in the mixture of products- $48.1 \%$ after 24 hours and $63.2 \%$ after 48 hours. The observed facts confirmed once more the hypothesis about competitive side reactions during the synthesis of $\beta$-alkyl aspartates (2).

\subsection{The Influence of Reaction Conditions}

The effect of solvent, temperature and duration of the ammonia addition reaction to alkyl maleates was determined approximately already during preliminary tests. The influence of the solvent was clearly pronounced - no reaction took place in methanol $(\mathrm{MeOH})$ solution at room temperature during 2 - 24 hours, while some addition product could be found in experiments made in tetrahydrofuran (THF) solutions. Therefore reaction time and temperature were increased in further experiments. The observed reaction rates were noticeably higher in the aprotic solvent THF than in the protic solvent $\mathrm{MeOH}$ solution at elevated temperatures, the best reaction conditions in these two solvents being considerably different. Surfactants (2) were obtained in acceptable preparative yields only in THF, while complex mixtures of products were always formed in $\mathrm{MeOH}$ solutions.

The second factor affecting the reaction-its temperature seems to have the most pronounced influence both on rates and on results of the addition reaction (Figure 2).

Our experiments were leading up to a conclusion that the best temperature interval for the addition reaction of ammonia was $40^{\circ} \mathrm{C}-60^{\circ} \mathrm{C}$, with the maximum at $\sim 50^{\circ} \mathrm{C}$. No isomerization of alkyl maleates (1) into alkyl fumarates (3) took place at this temperature during 24 hours (the very best selected time of syntheses), as well as the smallest ammonolysis of $\beta$-alkyl aspartates (2) could be observed in these conditions during this time; the mentioned side reactions increased considerably at temperatures above $60^{\circ} \mathrm{C}$.

The yield of the expected product (2) is closely related to its time (Figure 3).

The third factor influencing the addition reaction - its duration should not be underestimated. At least 24 hours were needed for the conversion of all the maleic hemiesters (1) into $\beta$-alkyl aspartates (2). The highest yields of the surfactants (2) (>65\%) could be obtained only when all the parameters (temperature, time, molar ratio of reagents) were kept in their strictly determined limits. Even small informalities from these limits decreased yields of the expected surfactants (2). A prolonged reaction time was considered as a disadvantage because it contributed to the elimination of ammonia from the surfactant (2) resulting in a formation of an alkyl

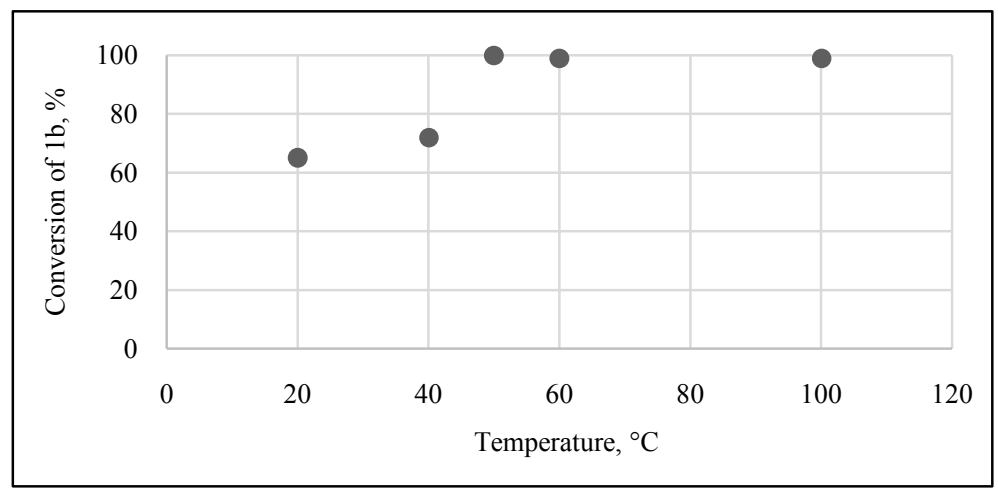

Figure 2. Conversion to the $\beta$-dodecyl maleate (1b) in the addition reactions of ammonia to it at various temperatures (according to ${ }^{1} \mathrm{H}$ NMR data of the isolated product (2b) made in THF solution during 24 hours with molar ratio $\left.\mathbf{1 b} / \mathrm{NH}_{3}=1: 30\right)$. 
fumarate (3), as well as ammonolysis of the $\beta$-ester group of the product (2) accompanied by the elimination of fatty alcohol (6).

The fourth key factor affecting the formation of qualitative surfactants $(2)$ is the molar ratio of reagents. It also has its optimal value, most likely, the very best molar ratio alkyl maleate/ammonia being 1:30 (Figure 4).

If a smaller molar ratio of reagents was applied, the product mixture contained a remarkable amount of the starting material - alkyl maleate (1) after the reaction, but if the ratio highly exceeds 1:30, a notable amount of eliminated fatty alcohol (6) could be found in the product mixture as the result of the above mentioned ammonolysis reaction (Figure 5).

The most undesirable side reaction - ammonolysis of $\beta$-alkyl aspartates (2) always accompanied their syntheses, even in the very best reaction conditions. Fatty alcohols (6) eliminate in these reactions, the yield of the last increasing with the rising reaction time. The decrease of the content of $\beta$-alkyl aspartate (2b) in the mixture of products and the corresponding increase of the content of fatty alcohol $(\mathbf{6 b})$ after every reaction is shown in Figure 6.

Hence, longer reaction time than necessary is also a disadvantage for the investigated addition reaction of ammonia. Accordingly, the best conditions for syntheses of discussed surfactants $-\beta$-alkyl aspartates (2) seem to be 24 hours in THF solution at $50^{\circ} \mathrm{C}$ with molar ratio alkyl maleate/ammonia $=1: 30$. Yields of isolated and crystallized surfactants exceed $65 \%$ in these conditions.

Two approaches were used for the characterization of synthesized zwitterionic surfactants (2) - confirmation

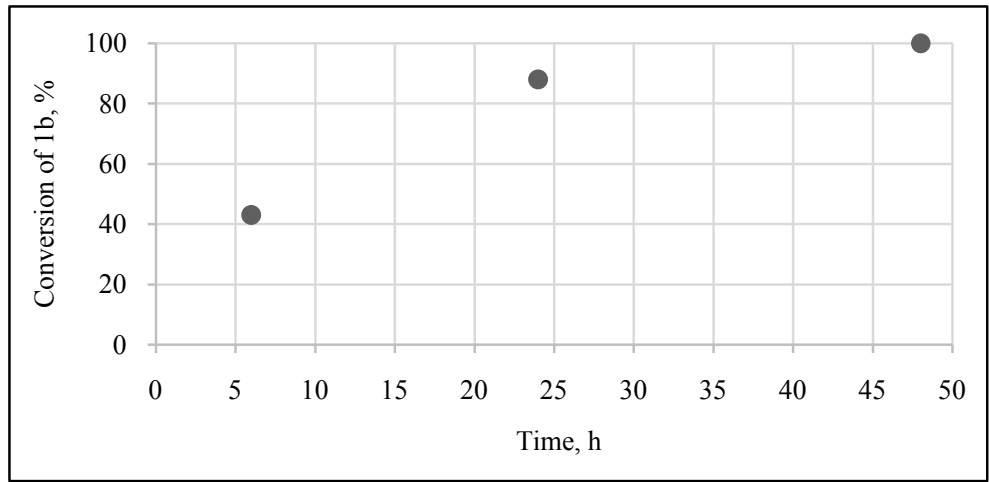

Figure 3. Conversion to the $\beta$-dodecyl maleate (1b) in the addition reactions of ammonia to it at various reaction times (according to ${ }^{1} \mathrm{H}$ NMR data of the isolated product $(\mathbf{2 b})$ made in THF solution at $50^{\circ} \mathrm{C}$ with molar ratio $1 \mathbf{b} / \mathrm{NH}_{3}$ $=1: 30)$.

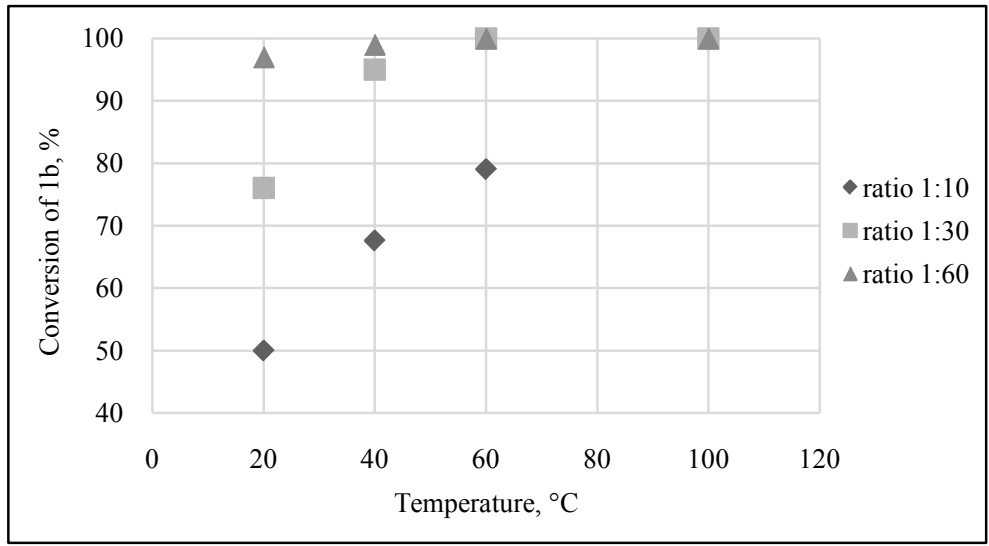

Figure 4. Conversion to the $\beta$-dodecyl maleate (1b) in the addition reactions of ammonia to it using various molar ratios of reagents and temperatures in the shortest time of the reaction (according to ${ }^{1} \mathrm{H}$ NMR data of the isolated product (2b) made in THF solution during 24 hours). 


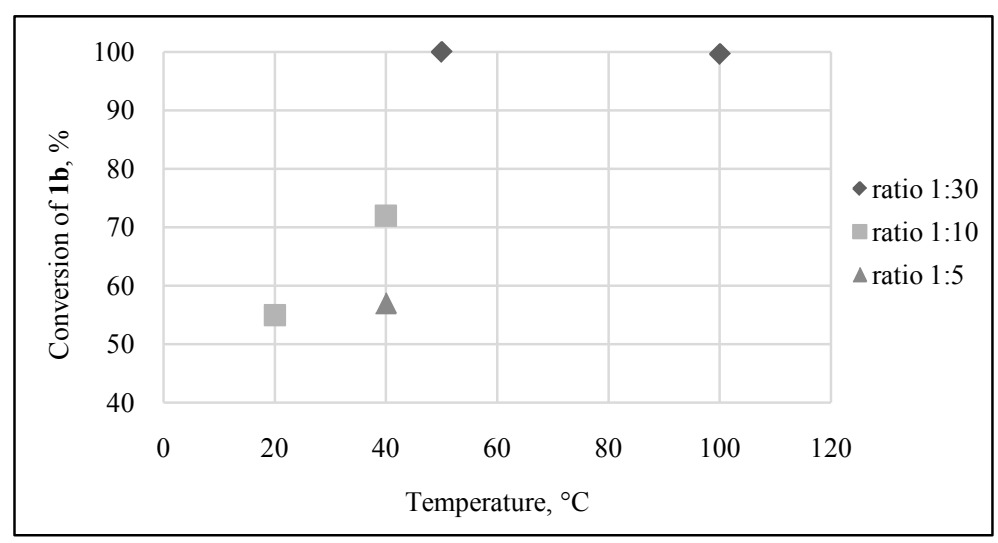

Figure 5. Conversion to the $\beta$-dodecyl maleate (1b) in the addition reactions of ammonia to it using various molar ratios of reagents and temperatures in longer time of the reaction (according to ${ }^{1} \mathrm{H}$ NMR data of the isolated product (2b) made in THF solution during 48 hours).

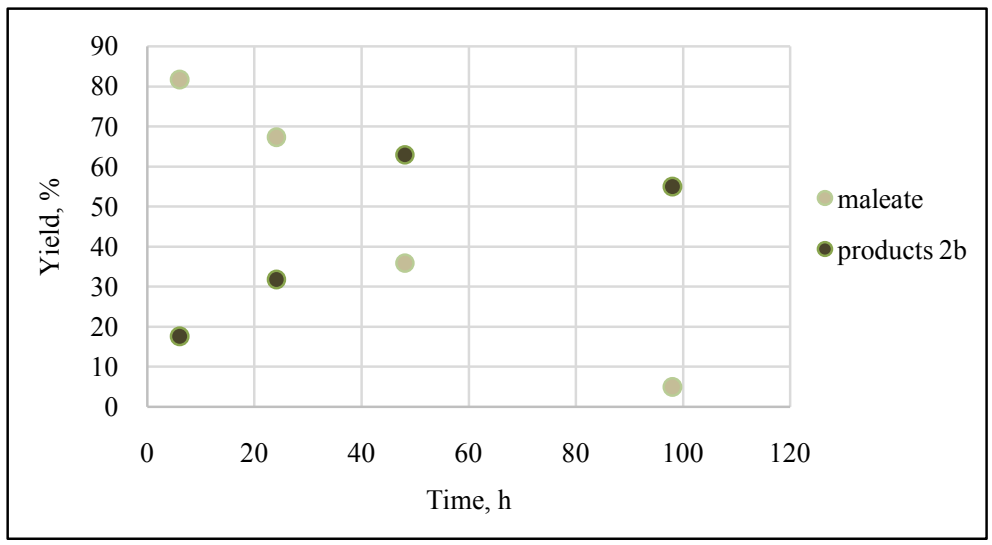

Figure 6. Comparison of yields of the isolated products: surfactant (2b) and the starting maleate (1b) in time (in THF at $50^{\circ} \mathrm{C}$ using molar ratios of reagents $\left.\mathbf{1 b} / \mathrm{NH}_{3}=1: 30\right)$.

of their structures was followed by appreciation of their application possibilities. Structures of surfactants (2) were characterized by their ${ }^{1} \mathrm{H}$ NMR and IR spectra. Elemental analyses were also used for their certification (Table 1). Only few application possibilities were examined for obtained surfactants (2) in the present communication - their surface properties, toxicity and biodegradability, in order to encourage other specialists to investigate and use these materials further.

The most characteristic signals in ${ }^{1} \mathrm{H}$ NMR spectra of surfactants (2) were those which confirmed the presence of the group of $\alpha$-amino acid- $\left(\mathrm{H}_{3} \mathrm{~N}^{+}\right)-\mathrm{CH}-\mathrm{CO}_{2}-$ at $3.90-3.87 \mathrm{ppm}$ and alkyl ester group- $\mathrm{CO}-\mathrm{O}-\mathrm{CH}-$ at $4.04-4.03 \mathrm{ppm}$ in the same molecule, together with the corresponding integral intensities of these signals. The most useful absorption peaks for characterization in the IR spectra of molecules of surfactants (2) were those caused by ester groups $v_{-\mathrm{O}-\mathrm{C}=\mathrm{O}}$, carboxylate anions $v_{\mathrm{CO} 2}$ and ammonium cations $v_{\mathrm{NH} 3}$ at $1732-1729,1617-$ 1615 , and $2874-2843 \mathrm{~cm}^{-1}$ correspondingly (Table 1 ).

\subsection{Surface Activity of $\beta$-Alkyl Aspartates}

The high application value of proposed surfactants (2) for washing and cleaning purposes was characterized firstly by measuring the surface tension values of their water solutions together with calculations of their critical micelle concentrations (Figure 7). Obtained data clearly certificated usefulness of $\beta$-alkyl aspartates (2) as surfactants - these esters with zwitterionic hydrophilic group convincingly manifested powerful surface activity (Table 2). 
Table 2. Surface properties of $\beta$-alkyl aspartates (2).

\begin{tabular}{ccc}
\hline \multirow{2}{*}{ Surfactant } & \multicolumn{2}{c}{ Surface properties } \\
\cline { 2 - 3 } & $\sigma^{*}, \mathrm{mN} / \mathrm{cm}$ & $\mathrm{CMC}, \mathrm{mg} \cdot \mathrm{L}^{-1}$ \\
\hline 2a & 64.3 & 26.7 \\
2b & 36.1 & 2.2 \\
2c & 35.6 & 1.8 \\
\hline
\end{tabular}

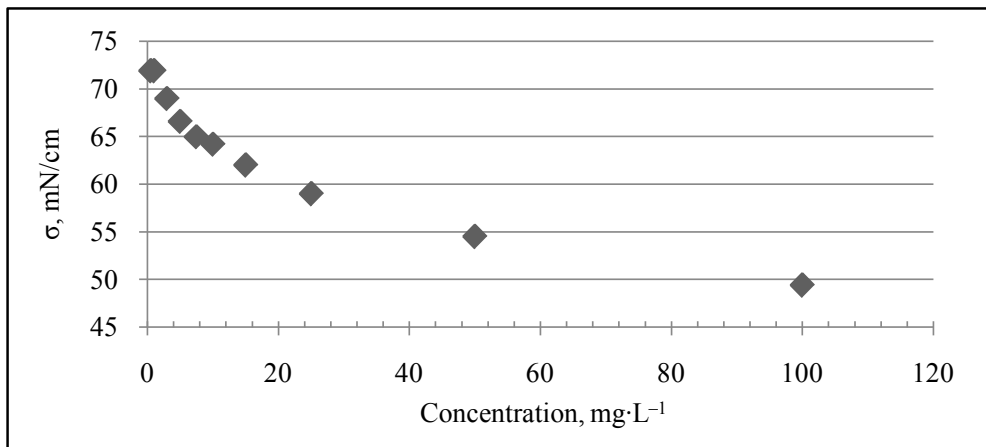

Figure 7. Results of surface tension measurements of the water solutions of a surfactant (2b).

Data in Table 2 and in Figure 7, as well as their comparison with literature data allow affirming that proposed surfactants (2) belong to materials with the highest surface activity available nowadays.

\subsection{Toxicity and Biodegradability of $\beta$-Alkyl Aspartates}

Surfactants (2) were expected to have low, if any, toxicity and high biodegradability, because of their pronounced similarity with natural amino acids. Results of the determination of these biological characteristics were tested only for the most representative surfactant from the investigated family $-\beta$-dodecyl aspartate (2b) in this communication.

Measurements of the toxicity of $\beta$-dodecyl aspartate (2b) were made using Daphtoxkit $\mathrm{F}^{\mathrm{TM}}$ Magna assay and Rapidtoxkit assay [14] [15]. Daphnia's are the most commonly used crustacean test species for determination of the effects of xenobiotics on primary consumers in freshwater aquatic ecosystems [14]. Inhibition effect of $\beta$ dodecyl aspartate (2b) on D. magna is shown in Figure 8.

The $\mathrm{EC}_{50}$ (half maximum effective concentration) for (2b) after $24 \mathrm{~h}$ and $48 \mathrm{~h}$ was found to be $15.0 \mathrm{mg} \cdot \mathrm{L}^{-1}$ and $7.0 \mathrm{mg} \cdot \mathrm{L}^{-1}$, respectively. This level of ecotoxicity can be considered as similar to most widely used surfactants nowadays, e.g., sodium monododecyl sulfate, which exhibited the $48 \mathrm{~h} \mathrm{EC}_{50}$ for D. magna in the range from 8.2 to $9.0 \mathrm{mg} \cdot \mathrm{L}^{-1}[17]$.

Rapidtoxkit microbiotest was applied for evaluating the toxic effect of $\beta$-dodecyl aspartate (2b) on freshwater crustacean T. platyurus. As a guideline, $30 \%$ inhibition of particle uptake was suggested as "a threshold signal" for the presence of "unwanted compounds" in the water sample [18] [19]. NałęczJawecki and coworkers [18] have compared the results on sodium dodecyl sulphate toxicity obtained in: 1) 60 min sublethal assay with anostracan crustaceans Thamnocephalus platyurus and 2) $24 \mathrm{~h}$ lethality assays with rotifers Brachionus calyciflorus. The toxicity values observed in the ingestion tests were very close to the mortality values. A strong correlation was reported between the two microbiotests performed with Thamnocephalus platyurus (Rapidtoxkit and Thamnotoxkit); a very good correspondence between the sublethal and the lethal effects, respectively was shown [19]. Therefore, the use of Rapidtoxkit for evaluating a potential toxicity of our investigated surfactants (2) can be considered as suitable.

Incubation of T. platyurus during $60 \mathrm{~min}$ in the presence of $\beta$-dodecyl aspartate (2b) tested in the concentration range from 0.78 to $50.00 \mathrm{mg} \cdot \mathrm{L}^{-1}$ has revealed the $30 \%$ inhibition of particle uptake by $T$. platyurus at 3.13 $\mathrm{mg} \cdot \mathrm{L}^{-1}$ of $\mathbf{2 b}$ (Figure 9). 


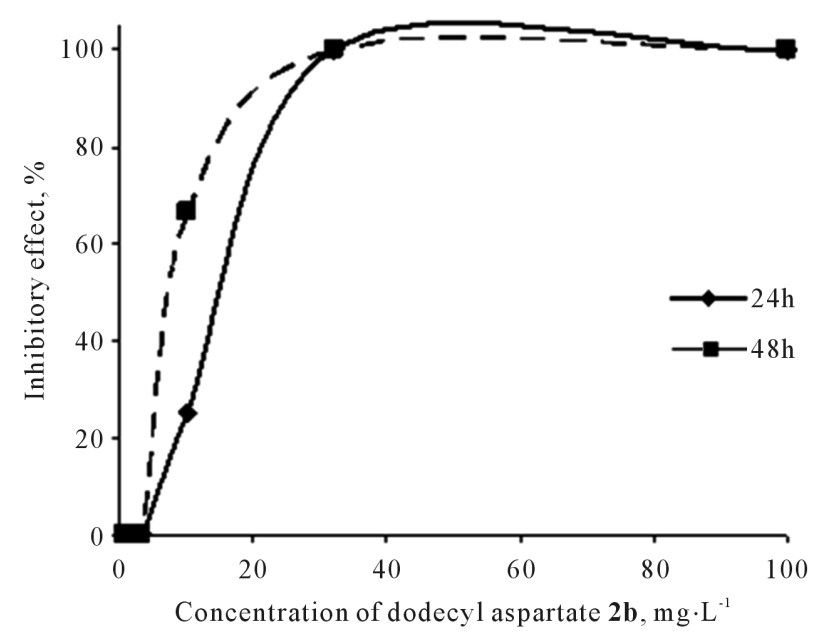

Figure 8. Inhibitory effect of $\beta$-dodecyl aspartate (2b) for Daphnia magna after $24 \mathrm{~h}$ and $48 \mathrm{~h}$ incubation tested by Daphtoxkit $\mathrm{F}^{\mathrm{TM}}$ Magna assay.

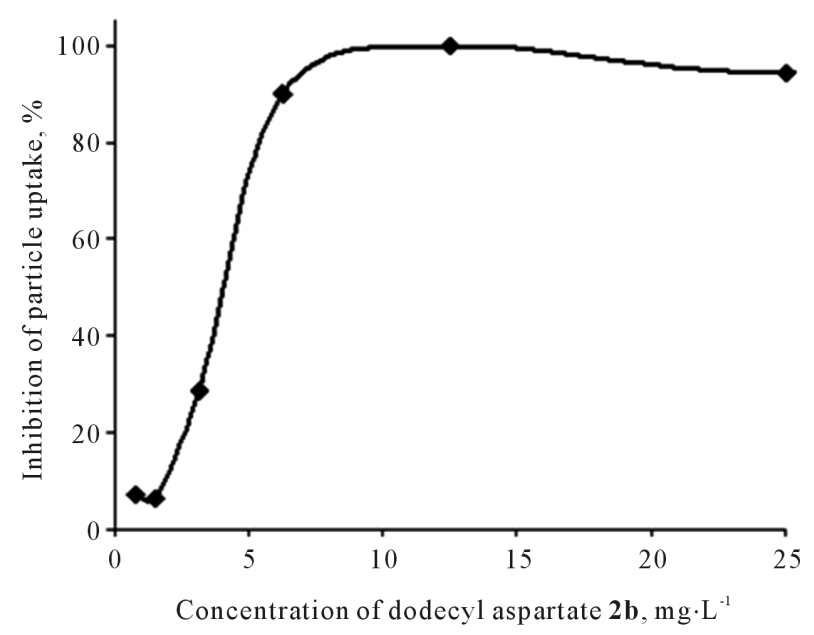

Figure 9. Mean percentage inhibition of particle uptake by Thamnocephalusplatyurus exposed to $\beta$-dodecyl aspartate (2b) during $60 \mathrm{~min}$ in Rapidtoxkit assay (MicroBio Tests Inc., Belgium).

Germination tests with Lepidiumsativum L., Raphanussativus L. and Secalecereale L. in the concentration range of surfactant (2b) from $0.5 \mathrm{mg} \cdot \mathrm{L}^{-1}$ to $100 \mathrm{mg} \cdot \mathrm{L}^{-1}$ did not reveal any inhibition effect (data not shown here).

Biodegradability of the $\beta$-dodecyl aspartate (2b) was determined by $\mathrm{CO}_{2}$ evolution in sealed bottles. OxiTop measurements simulate biological processes of wastewater treatment plants. The bacterial consortium with hydrocarbon degrading activity was incubated in our experiments in BH broth with the surfactant (2b) $\left(10 \mathrm{mg} \cdot \mathrm{L}^{-1}\right)$ as a sole carbon source. The oxygen consumption by bacterial culture in the sets with the surfactant (2b) and without it after $70 \mathrm{~h}$ incubation was found to be $19.8 \pm 4.0$ and $8.4 \pm 0.0 \mathrm{mg} \cdot \mathrm{O}_{2} \cdot \mathrm{L}^{-1}$, respectively. These data indicate to the potential biodegradability of the $\beta$-dodecyl aspartate (2b) by microorganisms. Further biodegradation experiments of these promising surfactants are needed, in particular, determination of $\mathrm{BOD}_{28}$ under OECD screening test conditions [20]. They are in progress at present.

\section{Conclusions}

1) Unsubstituted $\beta$-alkyl aspartates can be obtained in a simple addition reaction of ammonia to maleic he- 
miesters.

2) The reaction demands the maintenance of accurate reaction conditions - temperature $50^{\circ} \mathrm{C}$, reaction duration 24 hours and the stirring rate of the mixture $300 \mathrm{rpm}$.

3) Unsubstituted $\beta$-alkyl aspartates belong to materials with the highest surface activity available nowadays.

4) These surfactants show high biodegradability and very low toxicity when tested by standard methods.

\section{Acknowledgements}

We gratefully acknowledge European Regional Development Foundation, project No 2DP/2.1.1.1.0/14/APIA/ VIAA/016 for financial support, as well as Mr. L. Arbidans for measuring the surface tension and Dr. O. Muter for the determination of toxicity and biodegradability of investigated surfactants.

\section{References}

[1] Perez, L., Pinazo, A., Garcia, T.M., Lozano, M., Manresa, A., Vinardell, M.P., Mitjans, M., Pons, R. and Infante, R.M. (2009) Cationic Surfactants from Lysine: Synthesis, Micellization and Biological Evaluation. European Journal of Medicinal Chemistry, 44, 1884-1892. http://dx.doi.org/10.1016/j.ejmech.2008.11.003

[2] Albert, R., Danklmaier, J., Hoenig, H. and Kandolf, H. (1987) A Simple and Convenient Synthesis of $\beta$-Aspartates and $\gamma$-Glutamates. Synthesis, 1987, 635-637. http://dx.doi.org/10.1055/s-1987-28030

[3] Suzuk, M., Yumoto, M., Shirai, H. and Hanabusa, K. (2008) A Family of Low-Molecular-Weight Organogelators Based on Na, Ne-diacyl-L-Lysine: Effect of Alkyl Chains on Their Organogelation Behavior. Tetrahedron, 64, 1039510400. http://dx.doi.org/10.1016/j.tet.2008.08.061

[4] Boros, M., Koekoesi, J., Vamos, J., Koevesdi, I. and Noszal, B. (2007) Methods for Syntheses of N-Methyl-DL-Aspartic Acid Derivatives. Amino Acids, 33, 709-717. http://dx.doi.org/10.1007/s00726-006-0453-4

[5] Zilkha, A. and Bachi, M.D. (1959) Syntheses of N-Alkyl Aspartic Acids and N2-Alkyl- $\alpha$-Asparagines. The Journal of Organic Chemistry, 24, 1096-1098. http://dx.doi.org/10.1021/jo01090a015

[6] Bordes, R. and Holmberg, K. (2015) Amino Acid-Based Surfactants: Do They Deserve More Attention? Advances in Colloid and Interface Science, 222, 79-91. http://dx.doi.org/10.1016/j.cis.2014.10.013

[7] Rosen, M.J. and Kunjappu, J.T. (2012) Surfactants and Interfacial Phenomena. 4th Edition, John Wiley \& Sons Ltd., New York. http://dx.doi.org/10.1002/9781118228920

[8] Bordes, R. and Holmberg, K. (2009) Amino Acid-Based Surfactants. In: Somasundaran, P., Ed., Encyclopedia of Surface and Colloid Science, 2nd Edition, Taylor \& Francis, Goeteborg.

[9] Infante, M.R., Perez, I., Pinazo, A., Clapes, P. and Moran, M.C. (2003) Amino Acid-Based Surfactants. In: Holmberg, K., Ed., Novel Surfactants: Preparation, Applications and Biodegradability, Marcel Dekker, Inc., New York, Basel. http://dx.doi.org/10.1201/9780203911730.ch5

[10] Vulfson, E. (2001) Enzymatic Synthesis of Surfactants. In: Friedli, F.E., Ed., Detergency of Specialty Surfactants, Marcel Dekker, Inc., New York.

[11] Valivety, R., Gill, I.S. and Vulfson, E.N. (1998) Application of Enzymes to the Synthesis of Amino Acid-Based Bola and Gemini Surfactants. Journal of Surfactants and Detergents, 1, 177-185. http://dx.doi.org/10.1007/s11743-998-0017-3

[12] Valivety, R., Jauregi, P., Gill, I. and Vulfson, E. (1997) Chemo-Enzymatic Synthesis of Amino Acid-Based Surfactants. Journal of the American Oil Chemists' Society, 74, 879-886. http://dx.doi.org/10.1007/s11746-997-0232-8

[13] Li, Y. (2011) Synthesis and Physicochemical Study of Novel Amino Acid Based Surfactants. Master Thesis, Chalmers University, Goeteborg.

[14] (2016) Daphtoxkit F ${ }^{T M}$ Magna. Crustacean Toxicity Screening Test for Freshwater Standard Operational Procedure. http://www.microbiotests.be/SOPs/Daphtoxkit\%20magna\%20F\%20SOP\%20-\%20A5.pdf

[15] (2016) Rapidtoxkit. Microbiotest for Rapid Detection of Water Contamination. Standard Operational Procedure. http://www.microbiotests.be/SOPs/Rapidtoxkit\%20F\%20SOP\%20-\%20A5

[16] Laskovs, A., Laskovs, E., Grinbergs, A., Uljanovs, A. and Mutere, O. (2011) Consortium P1035 of MicroorganismsDestructors and Its Use for Degradation of Hydrocarbons. Latvian Patent No LV14347.

[17] Conway, R.A., Waggy, G.T., Spiegel, M.H. and Berglund, R.L. (1983) Environmental Fate and Effects of Ethylene Oxide. Environmental Science \& Technology, 17, 107-112. http://dx.doi.org/10.1021/es00108a009

[18] NałęczJawecki, G., Szczęsny, L., Solecka, D. and Sawicki, J. (2011) Short Ingestion Tests as Alternative Proposal for Conventional Range Finding Assays with Thamnocephalus platyurus and Brachionus calyciflorus. International 
Journal of Environmental Science and Technology, 8, 687-694. http://dx.doi.org/10.1007/BF03326253

[19] Törökné, A., Vasdinnyei, R. and Asztalos, B.M. (2007) A Rapid Microbiotest for the Detection of Cyanobacterial Toxins. Environmental Toxicology, 22, 64-68. http://dx.doi.org/10.1002/tox.20235

[20] (2014) OECD Guidelines for the Testing of Chemicals. Test No. 310: Ready Biodegradability- $\mathrm{CO}_{2}$ in Sealed Vessels (Headspace Test). http://dx.doi.org/10.1787/2074577x

\section{Submit or recommend next manuscript to SCIRP and we will provide best service for you:}

Accepting pre-submission inquiries through Email, Facebook, LinkedIn, Twitter, etc.

A wide selection of journals (inclusive of 9 subjects, more than 200 journals)

Providing 24-hour high-quality service

User-friendly online submission system

Fair and swift peer-review system

Efficient typesetting and proofreading procedure

Display of the result of downloads and visits, as well as the number of cited articles

Maximum dissemination of your research work

Submit your manuscript at: http://papersubmission.scirp.org/ 